\title{
Battery Electric Vehicle Driving and Charging Behavior Observed Early in the EV Project
}

\section{Society of Automotive Engineers World Congress 2012}

\author{
John Smart \\ Stephen Schey
}

U.S. Department of Energy

National Laboratory

operated by

Battelle Energy Alliance

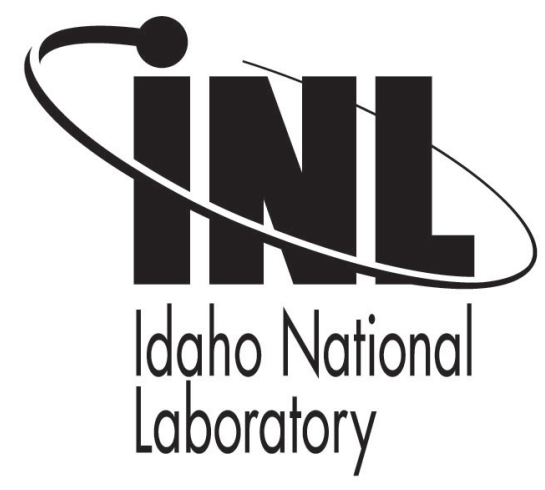

This is a preprint of a paper intended for publication in a journal or proceedings. Since changes may be made before publication, this preprint should not be cited or reproduced without permission of the author. This document was prepared as an account of work sponsored by an agency of the United States Government. Neither the United States Government nor any agency thereof, or any of their employees, makes any warranty, expressed or implied, or assumes any legal liability or responsibility for any third party's use, or the results of such use, of any information, apparatus, product or process disclosed in this report, or represents that its use by such third party would not infringe privately owned rights. The views expressed in this paper are not necessarily those of the United States Government or the sponsoring agency. 


\title{
Battery Electric Vehicle Driving and Charging Behavior Observed Early in The EV Project
}

\author{
John Smart \\ Idaho National Laboratory \\ Stephen Schey \\ ECOtality North America
}

\begin{abstract}
In 2010, a large-scale plug-in electric vehicle (PEV) infrastructure demonstration was launched to deploy an unprecedented number of PEVs and charging infrastructure. This demonstration, called The EV Project, is funded by the U.S. Department of Energy and led by ECOtality North America. ECOtality has partnered with Nissan North America and General Motors to deploy up to 8,300 Nissan LEAFTM battery electric vehicles and Chevrolet Volt extended-range electric vehicles, along with approximately 14,000 AC Level 2 and DC fast-charging units in 18 metropolitan areas across the United States.

ECOtality and the Idaho National Laboratory partnered to collect and analyze electronic data from EV Project vehicles and charging units. An early analysis of data from Nissan LEAFs enrolled in The EV Project was performed. The data set analyzed came from 2,903 privately owned vehicles, which logged over 10 million driving miles in 2011. On average, Nissan LEAF drivers drove 6.9 miles per trip and 30.3 miles per day. Median values were 4.0 and 26.8 miles, respectively. In environments without many public charging locations, LEAF drivers averaged 28.8 miles between consecutive charging events, with a median of 27.1 miles. The average and median number of times vehicles were charged per day driven were 1.05 and 0.99 charging events per day, respectively.

Analysis of charging location determined that $82 \%$ of charging events were conducted at the project participants' homes using their residential electric vehicle supply equipment. $18 \%$ of charging events were performed elsewhere. Despite the relatively low numbers of publicly available charging units, over $70 \%$ of vehicles were charged away from home. Most of those vehicles charged at many distinct locations, such as shopping centers, health clubs, restaurants, and business offices. Some of the most frequently and infrequently charged vehicles were charged exclusively at home or in public, but most supplemented home charging with away-from-home charging.
\end{abstract}

CITATION: Smart, J. and Schey, S., "Battery Electric Vehicle Driving and Charging Behavior Observed Early in The EV Project," SAE Int. J. Alt. Power. 5(1):2012, doi:10.4271/2012-01-0199.

\section{INTRODUCTION}

As concern about society's dependence on petroleumbased transportation fuels increases, many see plug-in electric vehicles (PEV) as enablers for diversifying transportation energy sources. These vehicles, which include plug-in hybrid electric vehicles (PHEV), extended-range electric vehicles (EREV), and battery electric vehicles (BEV), draw some or all of their power from electricity stored in batteries, which are charged by the electric grid. In order for PEVs to be accepted by the mass market, electric charging infrastructure also must be deployed. Charging infrastructure must be safe, convenient, and financially viable. Additionally, electric utilities must be able to manage PEV charging demand on the electric grid.

In 2010, the largest PEV infrastructure demonstration ever undertaken was launched. This demonstration, called The EV Project, is partially funded by the U.S. Department of Energy's Vehicle Technologies Program and led by ECOtality North America. ECOtality is installing approximately 14,000 AC Level 2 and DC fast-charging units in 18 metropolitan areas across the United States. ECOtality has partnered with Nissan North America and General Motors to enroll up to 8,300 Nissan LEAFTM BEVs and Chevrolet Volt EREVs sold in these areas in The EV Project.

ECOtality has partnered with the Idaho National Laboratory to collect and analyze electronic data from EV 
Project vehicles and charging units. This work will characterize vehicle consumer driving and charging behavior, evaluate the effectiveness of charging infrastructure placement, and quantify the impact of PEV charging on the electric grid. The ultimate goal of The EV Project is to capture lessons learned to enable the mass deployment of PEVs.

This paper will present summary statistics of in-use vehicle data collected from EV Project Nissan LEAF vehicles in 2011. The purpose of this paper is to describe early driving and charging behavior of Nissan LEAF drivers participating in The EV Project. This paper will serve as baseline for comparison to behavior observed later in the project as driver habits and charging infrastructure mature. Evaluation of charging infrastructure placement and the impact of Nissan LEAF and Chevrolet Volt charging on the electric grid will be addressed in other papers.

\section{BACKGROUND}

To accomplish its goals, The EV Project is installing a vast network of charging units, otherwise referred to as electric vehicle supply equipment (EVSE). This charging infrastructure is being concentrated in 18 cities in 6 U.S. states and the District of Columbia. Figure 1 identifies these cities.

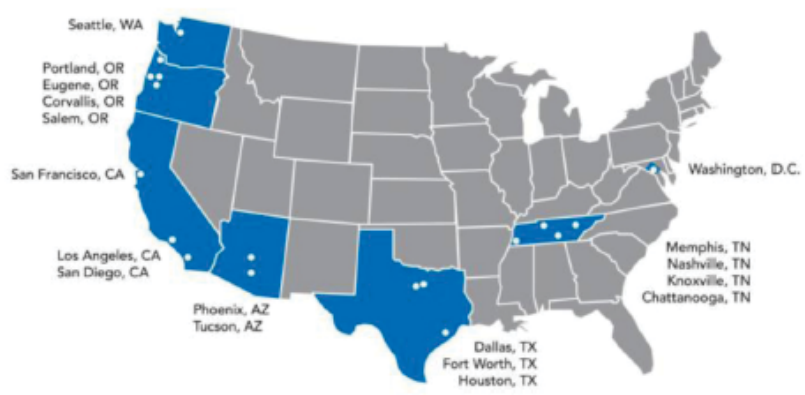

Figure 1. Cities participating in the EV Project

ECOtality partnered with Nissan North America and General Motors to invite Nissan LEAF and Chevrolet Volt customers in EV Project cities to participate in The EV Project. Vehicle owners who qualify to participate in The EV Project receive a residential EVSE at no cost. In addition, most, if not all, of the installation cost is paid for by The EV Project. In return, project participants agree to allow data collection from their vehicles and the EVSE they use. Data will be collected from EV Project vehicles and charging units through March 2013.

The EV Project is also installing several thousand commercial EVSE in and between these cities. This network of publicly accessible charging units will include approximately 200 dual port DC fast chargers. In each project area, ECOtality led development of an infrastructure placement plan, relying on collaboration with electric utilities, state and local authorities, and other area stakeholders. These teams employed a systematic process for selecting public charging locations to maximize benefit to vehicle owners, public charging unit owners, and the community. This process targeted locations where people shop, play, or gather for periods of 1 to 3 hours. The project's EVSE deployment phase is currently underway and will end in mid-2012.

\section{EV PROJECT VEHICLES AND CHARGING INFRASTRUCTURE}

The EV Project uses the Blink brand of EVSE, which is manufactured by ECOtality. The Blink product line consists of AC Level 2 residential and commercial EVSE and a DC Level 2 commercial fast charger. The AC Level 2 units operate at 240-VAC single phase, at charge rates up to 7.2 $\mathrm{kW}$. The DC fast charger is a CHAdeMO-compliant, 480volt, three-phase AC input unit, capable of charging at up to $60 \mathrm{~kW}$. All Blink units have internal energy meters and touch-screen user interfaces, allowing user-controlled charge scheduling. All units are networked, which enables data collection, user authentication, multiple payment options (for commercial units), and additional functionality $[\underline{1}, \underline{2}]$.

The Nissan LEAF is a BEV with a $24-\mathrm{kWh}$ battery pack. All Nissan LEAFs participating in the EV Project have SAE J1772@ compliant, AC Level 2 charging inlets and DC fast charger inlets that are compatible with the CHAdeMO connector [ $\underline{3}$ ]. Additionally, the Nissan LEAF is capable of charging at any standard 120-volt outlet, using the AC Level 1 cordset supplied with the vehicle [4]. Driving data are collected from each participating Nissan LEAF via the vehicle telematics system.

The Chevrolet Volt is an EREV with $16-\mathrm{kWh}$ battery pack. All Chevrolet Volts participating in the EV Project have SAE J1772 compliant, AC Level 2 charging inlets. (The Volt does not accept DC fast charging.) [ 5] The manufacturer expects Volt owners to sometimes charge at standard 120volt outlets, using the supplied AC Level 1 portable EVSE [6]. Driving data are collected from each participating Chevrolet Volt via the vehicle telematics system.

\section{PROJECT STATUS}

Deployment of the EV Project's first residential EVSE coincided with initial Nissan LEAF sales in December 2010. Deployment of residential EVSE and enrollment of Nissan LEAF drivers into the project began in earnest in spring 2011. Commercial EVSE installation and Chevrolet Volt driver enrollment began in summer 2011. Table 1 presents the number of EV Project vehicles enrolled and Blink EVSE deployed by region at the end of December 2011. 
Table 1. EV Project vehicle and EVSE deployment through December 2011

\begin{tabular}{|l|c|c|c|c|}
\hline \multicolumn{1}{|c|}{$\begin{array}{c}\text { EV Project } \\
\text { Region }\end{array}$} & $\begin{array}{c}\text { Number } \\
\text { of } \\
\text { Nissan } \\
\text { LEAFs } \\
\text { Enrolled }\end{array}$ & $\begin{array}{c}\text { Number } \\
\text { of } \\
\text { Chevrolet } \\
\text { Volts } \\
\text { Enrolled }\end{array}$ & $\begin{array}{c}\text { Number of } \\
\text { Residential } \\
\text { EVSE } \\
\text { Installed }\end{array}$ & $\begin{array}{c}\text { Number of } \\
\text { Commercial } \\
\text { EVSE } \\
\text { Installed }\end{array}$ \\
\hline Phoenix, AZ & 213 & - & 198 & 57 \\
\hline Tucson, AZ & 66 & - & 63 & 14 \\
\hline $\begin{array}{l}\text { Los Angeles, } \\
\text { CA }\end{array}$ & 379 & 2 & 303 & 7 \\
\hline San Diego, CA & 568 & 50 & 565 & 39 \\
\hline $\begin{array}{l}\text { San Francisco, } \\
\text { CA }\end{array}$ & 1,066 & - & 858 & 6 \\
\hline $\begin{array}{l}\text { Washington, } \\
\text { D.C. }\end{array}$ & 0 & 27 & 2 & 0 \\
\hline Oregon & 365 & - & 335 & 946 \\
\hline $\begin{array}{l}\text { Chattanooga, } \\
\text { TN }\end{array}$ & 35 & - & 35 & 23 \\
\hline Knoxville, TN & 66 & - & 60 & 44 \\
\hline Memphis, TN & 22 & - & 16 & 2 \\
\hline Nashville, TN & 289 & - & 275 & 59 \\
\hline $\begin{array}{l}\text { Dallas/ } \\
\text { Ft.Worth, TX }\end{array}$ & - & 38 & 5 & 35 \\
\hline Houston, TX & - & 40 & 18 & 4 \\
\hline $\begin{array}{l}\text { Washington } \\
\text { State }\end{array}$ & 597 & 0 & 563 & 83 \\
\hline Total & 3,666 & 157 & 3,296 & 467 \\
\hline
\end{tabular}

In Table 1, dashes indicate no vehicles are planned for a project region. The number of vehicles shown in Table 1 represents vehicles which have been enrolled in the EV Project and from which data are being collected. This is a subset of the total sales of Nissan LEAFs and Chevrolet Volts in these regions.

\section{INFLUENCES ON BEHAVIOR}

As shown in Table 1, at this stage in the project, the majority of EVSE installed were residential units. Public infrastructure available for use by project participants was limited to a small number of Blink AC Level 2 EVSE and non-EV Project EVSE from other manufacturers installed in project cities. Therefore, driving and charging behavior exhibited by LEAF drivers at this early stage in the project is indicative of behavior in environments with little public charging infrastructure.

It is important to point out other conditions that may influence driving and charging behavior. Many BEV owners currently participating in The EV Project are early in their ownership experience. Their behavior may change over time as they become accustomed to their new vehicle and the nuances of its new technology, especially its method of refueling. Behavior may change and habits may form as what was once novel becomes routine. Furthermore, the PEV market, as a whole, is young; therefore, any purchaser of a plug-in vehicle at this point would be classified as an early adopter. These consumers often have different interests and attentions than other consumers. It is generally accepted that their use of a product is not representative of the mass consumer market. This paper does not attempt to divide project participants into categories. Instead, it suffices to say that the results presented herein are representative of an early market.

\section{RESULTS}

Summary metrics and distributions were calculated to quantify Nissan LEAF owner driving and charging behavior and the relationship between driving and charging. Results were based on a set of in-use electronic data collected from 2,903 Nissan LEAFs enrolled in The EV Project from January through December 2011. These vehicles were located in each of the project regions shown in Table 1.

\section{OBSERVED DRIVING BEHAVIOR}

Table 2 presents summary metrics describing the driving of these vehicles, including the relationship between driving and charging frequency.

Table 2. Driving summary metrics

\begin{tabular}{|l|r|}
\hline Number of trips & $1,454,220$ \\
\hline Total distance driven (mi) & $10,000,316$ \\
\hline Mean / median trip distance (mi) & $6.9 / 4.0$ \\
\hline $\begin{array}{l}\text { Mean / median distance driven per } \\
\text { vehicle day driven (mi) }\end{array}$ & $30.3 / 26.8$ \\
\hline $\begin{array}{l}\text { Mean / median number of trips } \\
\text { between charging events }\end{array}$ & $4.2 / 3$ \\
\hline $\begin{array}{l}\text { Mean / median distance driven } \\
\text { between charging events (mi) }\end{array}$ & $28.8 / 27.1$ \\
\hline
\end{tabular}

The mean and median values in Table 2 are statistically significant, in that they come from a large data set of over 10 million logged miles. It is important to recognize, however, that the contribution of miles from each vehicle is relatively small. This is because the vehicles represented in this data set joined the project throughout 2011 , with the majority enrolled in the second half of the year. Therefore, the statistics shown in Table 2 describe behavior of vehicle owners still new in their Nissan LEAF ownership experience (and perhaps new to electric vehicles all together).

Table 2 shows that at this point in the project, LEAFs were driven 6.9 miles per trip on average, with a median trip distance of $4.0 \mathrm{mi}$. This indicates that the underlying distribution is left-skewed, rather than normally distributed. The other metrics in Table 2 exhibit this same trend. Therefore, the distributions of data that make up the several metrics presented in Table 2 were examined to appreciate the range of variation in behavior. Figure 2 shows the distribution of trip distance observed in the data set. 


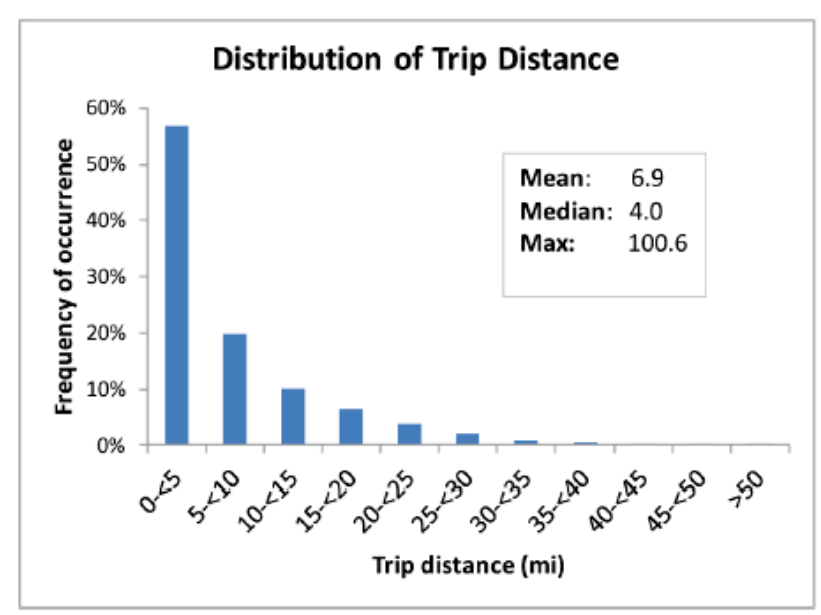

Figure 2. Distribution of trip distance

This figure shows that over half of all trips were less than 5 miles. This is reasonable, given that all vehicles enrolled in The EV Project are based in densely populated metropolitan areas. The maximum trip distance observed was 100.6 miles, suggesting that the Nissan LEAF is capable of driving at least 100 miles on a single charge. This is consistent with the manufacturer's expected range of the Nissan LEAF, which is 62 to 138 miles on a single full charge, depending upon driving conditions [7].

To better understand driver behavior with respect to BEV driving range, one must examine the sum of all distance traveled between consecutive charging events. This distance may be traveled in multiple trips. Figure 3 gives this distribution.

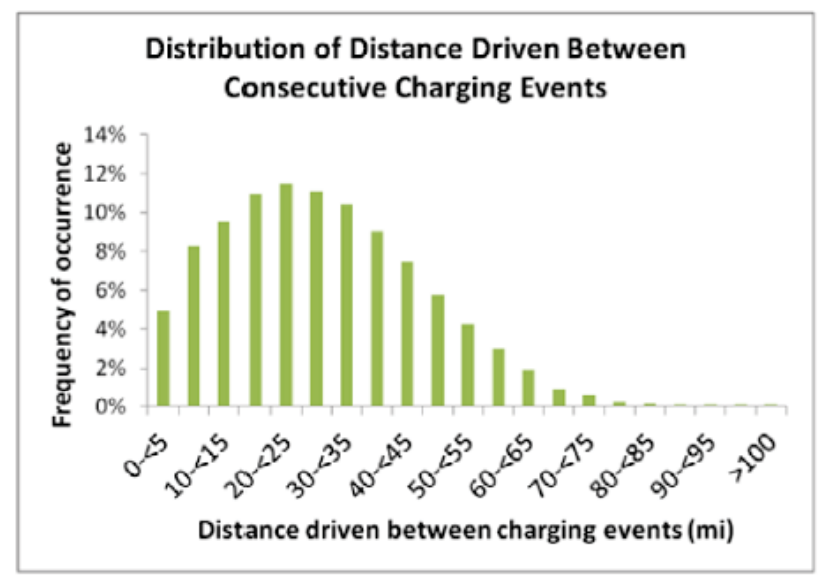

Figure 3. Distribution of distance between charging events

Figure 3 indicates that drivers frequently charged their vehicles well before reaching the manufacturer's expected range. It is not yet clear what is causing this conservative behavior with respect to range. It is tempting to speculate that this could indicate drivers are consciously limiting their driving between charging to avoid the risk of fully depleting their battery before the next charging opportunity. However, the opposite may be the case. Drivers may be finding convenient opportunities to charge their vehicles and they are taking them, regardless of the available driving range remaining. For example, if drivers were to charge once each night on days when the vehicle is driven, Figure 3 would simply be a representation of EV Project participants' typical daily driving patterns. The distribution of distance driven per vehicle day driven is depicted in Figure 4. Indeed, it is similar to Figure 3 , with a median value of 26.8 miles per day. Whether drivers are limiting their daily driving due to concerns about range remains a question, which will be explored in future works. Nevertheless, some drivers found reasons to use a large portion of the vehicle's range; the maximum distance driven between charging events observed was 101 miles.

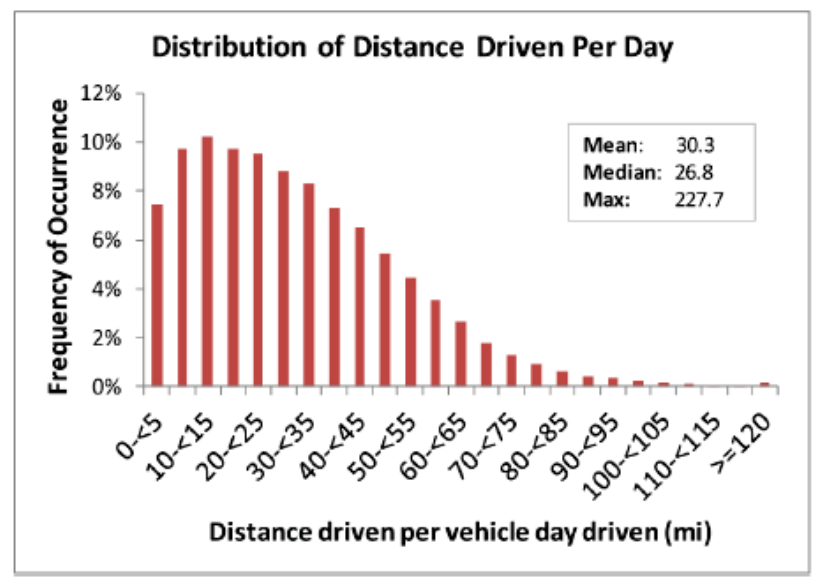

Figure 4. Distribution of distance driven per vehicle day driven

\section{OBSERVED CHARGING BEHAVIOR}

Table 3 gives the total number of charging events in the data set, as well as the mean and median number of charging events per vehicle per day driven.

Table 3. Charging summary statistics

\begin{tabular}{|l|l|}
\hline $\begin{array}{l}\text { Total number of charging } \\
\text { events }\end{array}$ & 347,222 \\
\hline $\begin{array}{l}\text { Mean / median number of } \\
\text { charging events per vehicle } \\
\text { day driven }\end{array}$ & $1.05 / 0.99$ \\
\hline
\end{tabular}

Table 3 shows that BEV drivers in The EV Project thus far have charged once per day, on average. This is consistent with the observations described in the preceding section, 
where distance driven between charging events is close to distance driven per day.

The distribution of the average number of charging events performed per day driven for each vehicle is shown in Figure 5. This shows wide variation in charging behavior from vehicle to vehicle, from 0.15 charges per day (about once per week) to 3.2 times per day.

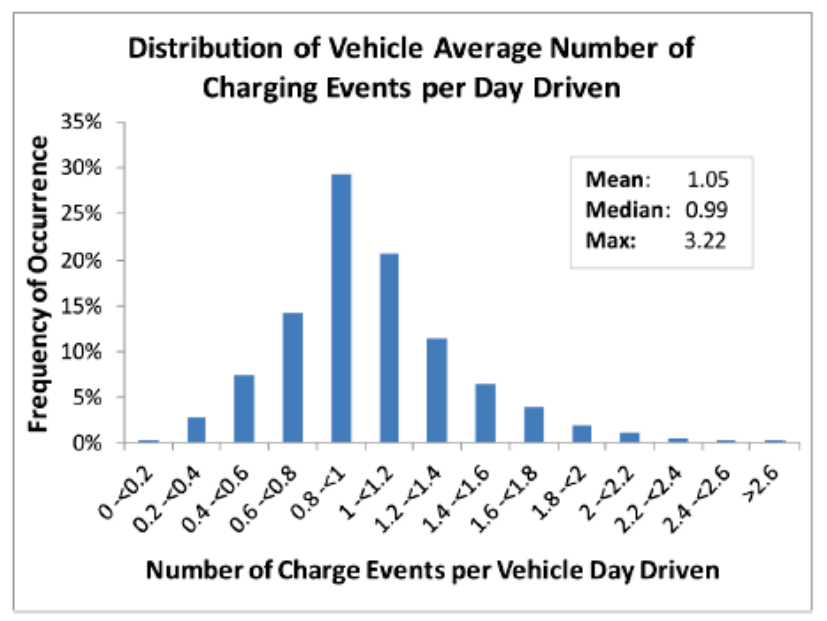

Figure 5. Distribution of charging events per vehicle day driven

There are many conceivable reasons why charging frequency varies from vehicle to vehicle (or even from driver to driver). A previous study of conversion PHEV drivers found that drivers with the most sophisticated understanding of their vehicles and their daily driving habits typically charged their vehicles less frequently than others. This was the case because these drivers understood how much they needed to charge their vehicles to meet their driving requirements and they chose not to charge more often than was necessary []ㅡ. This may explain why some Nissan LEAF drivers have average charging frequency of much less than once per day.

Perhaps some who charge their vehicles once per day or more are motivated to have a full battery, in the event that they may feel the need to drive farther than expected on any given day. A "just-in-case" mentality may be more prevalent in areas without many public charging options. Finally, there is evidence that some drivers must charge multiple times per day to meet their driving needs. For example, one vehicle drove 227 miles in one day, as seen in Figure 4.

One of the answers The EV Project intends to provide is where PEV drivers charge their vehicles, when provided with the options of both home and public charging. In order to understand public EVSE usage and to establish a baseline for comparison later in the project, the frequency of charging by location was examined using GPS data. Figure 6 shows the percentage of charging events in the data set that were performed at home (i.e., the BEV owner's residence) versus the charging events performed away from home. Away-from- home charging can be conducted using a dedicated publicly available EVSE unit or any standard 120-volt outlet.

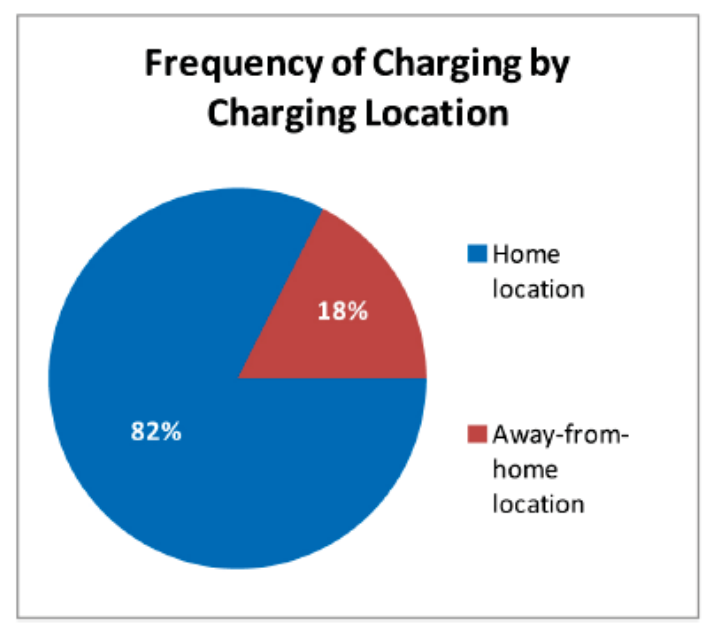

Figure 6. Frequency of charging by charging location

Although the majority of charging was performed at home, it is somewhat surprising to see that $18 \%$ of charging events were performed away from home. Geographic information systems tools were used to further investigate where the vehicles charged. Over $70 \%$ of vehicles in the data set charged away from home at EV Project Blink AC Level 2 EVSE, non-project EVSE from other manufacturers, or using the AC Level 1 cordset. Nearly all those vehicles charged at more than one location, and most charged at five or more distinct locations. Away-from-home charging locations observed included shopping centers, health clubs and spas, bars and restaurants, office buildings, and other homes. Vehicles which charged away from home more than at home tended to charge most often at a single workplace charging location. The vast majority of those vehicles also used other away-from-home charging locations.

Charging locations of vehicles which averaged well over one charging event per day were examined. Some of these vehicles charged exclusively at home. Most supplemented home charging with away-from-home charging. A small number of these frequently charged vehicles were nearly always charged away from home. Vehicles which were charged much less than once per day exhibited this same variation in charging location mix.

In the previous section, distance driven between charging events was examined and compared to the expected range of the vehicle. Another way to analyze driving and charging tendencies with respect to vehicle range is to look at the vehicle battery pack's state of charge (SOC) at the start and end of charging events. Battery SOC at the start of charging is an indicator of how much of the battery pack's capacity had been depleted prior to charging. Figure 7 shows the distribution of battery SOC at the start of charging for all charging events in the data set. This distribution is given for 
home and away-from-home charging events separately for comparison.

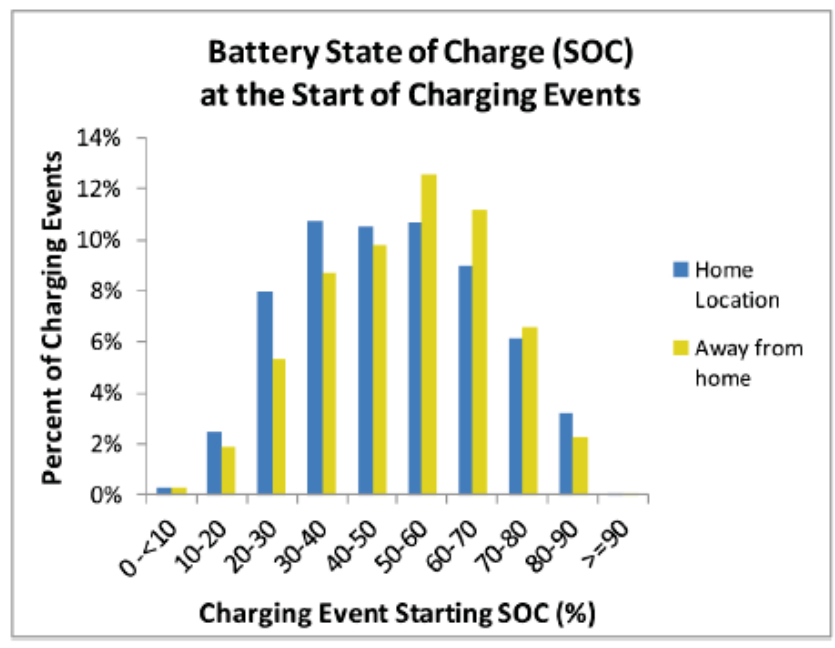

Figure 7. Distribution of battery pack SOC at the start of charging by charging location

Both distributions are fairly wide but fall off quickly at each extreme, indicating that drivers were most likely to charge their vehicles when SOC was between $20 \%$ and $80 \%$. The starting SOC distribution when charging at home is shifted to the left of the away-from-home distribution, suggesting perhaps that drivers were likely to drive farther in order to return home to charge (either by choice or out of necessity due to lack of public infrastructure).

The distribution of battery SOC at the end of charging represents how "full" the pack was when the driver began the first trip after charging. Figure 8 gives this distribution, breaking out home and away-from-home charging events.

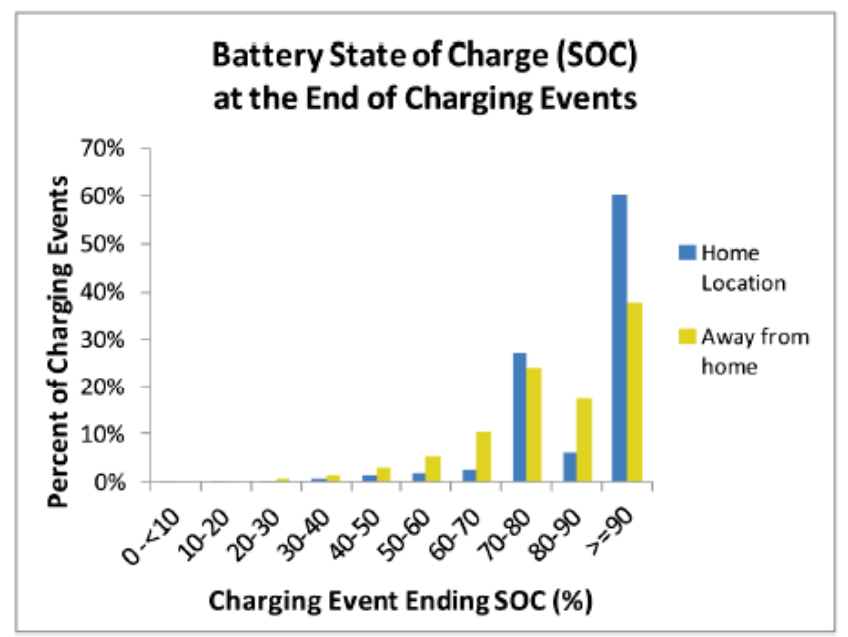

Figure 8. Distribution of battery pack SOC at the end of charging by charging location
Note the spike in occurrence of charging events ending between 70 and $80 \%$ SOC. Inspection of the data found that nearly all points in this range fell between 78 and $80 \%$ SOC. This is because the Nissan LEAF offers its owners the option of ending charging once the battery SOC reaches $80 \%$. Nissan states that this option can be used to preserve battery life when full driving range is not needed [9]. While it is not possible with the data collected to discern which drivers have opted to limit charging to $80 \% \mathrm{SOC}$, it is clear that the majority of home charging events resulted in a fully charged or nearly fully charged battery pack. Away-from-home charging ended with lower SOC in general, but most charging events were completed with greater than $70 \%$ SOC.

\section{SUMMARY/CONCLUSIONS}

An early analysis of data from Nissan LEAFs enrolled in The EV Project was performed. The data set analyzed came from 2,903 privately owned vehicles, which logged over 10 million driving miles in 2011. On average, Nissan LEAF drivers drove 6.9 miles per trip and 30.3 miles per day. Median values were 4.0 and 26.8 miles, respectively. In environments without many public charging locations, these $\mathrm{BEV}$ drivers averaged 28.8 miles between consecutive charging events, with a median of 27.1 miles. The average and median number of times vehicles were charged per day driven were 1.05 and 0.99 charging events per day, respectively.

Distributions of trip distance, distance driven between charging events, distance driven per day, charging event frequency per day driven, and battery SOC at the start and end of charging were examined to find a wide variation in driving and charging behavior. Data indicate that thus far in The EV Project, drivers have typically charged their vehicles frequently relative to distance driven, maintaining relatively high battery state of charge.

Analysis of charging location determined that $82 \%$ of charging events were conducted at the project participants' homes using their residential EVSE. $18 \%$ of charging events were performed elsewhere, either using publicly available EVSE, or with the vehicles' AC Level 1 cordsets plugged into standard $120-\mathrm{V}$ outlets. Despite the relatively low numbers of publicly available EVSE, over $70 \%$ of vehicles charged away from home. Nearly all those vehicles charged at more than one location, and most charged at five or more distinct locations. Away-from-home charging locations observed were diverse and included workplace charging. Nearly all vehicles that charged at a workplace location also charged at other away-from-home locations, such as shopping centers, health clubs, and restaurants. Vehicles which were charged frequently and vehicles which were charged infrequently exhibited similar variation in the mix of charging locations. Some charged exclusively at home or in public, but most supplemented home charging with away-from-home charging. 
These results serve as a baseline for comparison to future works, which will examine driving and charging behavior in environments with much higher public charging available. As more understanding is gained about how PEV drivers are using their vehicles, infrastructure placement plans can be updated and impact on the electric grid can be assessed.

\section{REFERENCES}

1. Blink,, "Level 2 Wall Mount Charger," http://www.blinknetwork.com/ brochures $/ 12$-wall-mount-charger/index.htm1, Sept. 2011. 2. Blink, "DC Fast Charger," http://www. blinknetwork.com/brochures/dc-

3. The EV Project, "The EV Project FAQs," http://www.theevproject.com/

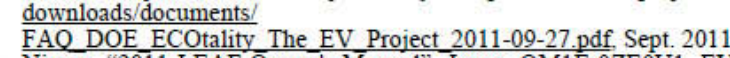

4. Nissan, "2011 LEAF Owner's Manual", Japan, OM1E-0ZE0U1, EV11, March 2011.

5. Brooke, L., "Chevrolet Volt AEI Best Engineered Vehicle 2011," Automotive Engineering International: April 5, 2011.

6. Argote, T. and Kissel, G., "Development of Chevrolet Volt Portable EVSE," SAE Technical Paper 2011-01-0878, 2011, doi: 10.4271/2011-01-0878

7. Nissan, "Nissan LEAF," http://www.nissanusa.com/leaf-electric-car/ index\#/leaf-electric-car/theBasicsRange/index, Sept. 2011.

8. Smart, J., Davies, J., Shirk, M., Quinn, C., Kurani, K., "Electricity Demand of PHEVs Operated by Private Households and Commercial Fleets: Effects of Driving and Charging Behavior," EVS-25, Shenzhen, China, Nov 5, 2010

9. "2011 LEAF Owner's Manual," Japan, 2011, pgs CH-21-23.

\section{CONTACT INFORMATION}

John Smart

john.smart@inl.gov

Steve Schey

sschey@ecotality.com

\section{ACKNOWLEDGMENTS}

Funding for The EV Project is provided in part by the U.S. Department of Energy's Vehicle Technologies Program through a grant from the American Reinvestment and Recovery Act.

\section{DEFINITIONS/ABBREVIATIONS}

\section{PEV}

EREV

plug-in electric vehicle

BEV

extended-range electric vehicle

EVSE

battery electric vehicle

SOC

electric vehicle supply equipment

state of charge

\section{DISCLAIMER}

References herein to any specific commercial product, process, or service by trade name, trademark, manufacturer, or otherwise, does not necessarily constitute or imply its endorsement, recommendation, or favoring by the U.S.
Government, any agency thereof, or any company affiliated with the Idaho National Laboratory. INL/CON-10-18967 